\title{
End of the old guard?
}

DOI:

10.1038/nrc2000

\section{URLs \\ Links \\ p53}

http://www.ncbi.nlm.nih.gov/ entrez/query.fcgi?db=gene\&c $\mathrm{md}=$ Retrieve\&dopt=full reportElist_uids $=7157$

\section{p19ARF}

http://www.ncbi.nlm.nih.gov/ entrez/query.fcgi?db=gene\&c $\mathrm{md}=$ RetrieveEdopt=full report\&list_uids $=12578$
The 'guardian of the genome', p53, rapidly induces both cell-cycle arrest and apoptosis in response to DNA damage, thereby preventing mutated cells from becoming tumours. This dogma is challenged by results from Gerard Evan and colleagues and Manuel Serrano and colleagues, who show that these early responses can be dispensed with and that the stabilization and activation of p53 through the oncogene-mediated activation of the tumour suppressor $\mathrm{p} 19^{\mathrm{ARF}}$ is crucial for tumour suppression.

Exposure of p53 wild-type mice to $\gamma$-radiation induces widespread p53-mediated apoptosis in radiosensitive tissues, and these mice are significantly protected from lymphomagenesis compared with p53-deficient mice. Evan and colleagues had previously constructed a p53 knockin mouse in which the function of p53 is regulated by the addition of 4-hydroxytamoxifen (4-OHT). p53 is not activated by this treatment, but is merely rendered ready for action. They used these mice to determine when $\mathrm{p} 53$ needs to function in order to suppress lymphoma development in response to $\gamma$-radiation.

p53 knock-in mice were treated with 4-OHT or sham treated for 6 days before treatment with $2.5 \mathrm{~Gy}$ of total body $\gamma$-radiation. The mice treated with 4-OHT showed classical p53-mediated responses, including apoptosis in the lymphoid tissue and intestinal epithelium — the sham treated mice were devoid of these pathologies. These 2 groups of mice were then monitored for the onset of lymphoma. Surprisingly, the mice that were initially treated with 4-OHT prior to radiation showed no protection from lymphomagenesis compared with the sham treated mice, indicating that the widespread p53-mediated apoptosis seen in the lymphoid compartment after radiation did not protect from lymphoma development. As global DNA damage was resolved with identical kinetics in both wild-type and p53 knock-in mice treated with 4-OHT, the authors investigated whether p53 needs to function later to suppress tumours after the initial DNA damage has been resolved. p53 knock-in mice were irradiated as before, but this time $\mathrm{p} 53$ was not restored until 8 days after radiation treatment. These mice showed no signs of radiation-induced pathologies and were significantly protected from lymphomagenesis.

So, if the early p53-dependent response to DNA damage is not required, how does p53 function as a tumour suppressor? In theory, the initial radiation insult might result in unresolved DNA damage that persistently triggers p53 activation, or it might result in oncogenic mutations that activate p19ARF, which in turn activates $\mathrm{p} 53$. Importantly, p19 $9^{\mathrm{ARF}}$ is only activated in response to oncogene activation and not DNA damage. The authors crossed Arf-deficient mice with p53 knock-in mice and exposed these mice to $\gamma$-radiation followed by the restoration of $\mathrm{p} 53$ function 8 days later. These mice showed no protection against lymphoma development. This result indicates that the $\mathrm{p} 19^{\mathrm{ARF}}-\mathrm{p} 53$ pathway is crucial for tumour suppression. The authors suggest that $\mathrm{p} 19^{\mathrm{ARF}}$ is activated in prelymphoma cells by oncogenic mutations induced as a result of exposure to $\gamma$-radiation.

A similar conclusion has been reached by Serrano and colleagues. They treated Arf-null mice that express one extra physiologically reg- ulated copy of the $\operatorname{Tr} p 53$ gene ( $\mathrm{p} 53^{\text {super }}$ mice) or are wild type for p53 with either $\gamma$-radiation or a DNA-damaging carcinogen, or simply analysed the incidence of spontaneous tumour development. All of the Arf-null mice had a normal p53 DNA-damage response, but could not activate p53 in response to the deregulated expression of an oncogene. p53 3 super mice are known to be more resistant to tumour formation, but this was not the case in the $\mathrm{p} 53^{\text {super }} / \mathrm{ARF}$-null mice. These mice developed tumours at an identical rate to p53 wild-type/ARFnull mice, showing that the protection afforded by $\mathrm{p} 53$ against tumour development is ARF dependent.

These data are consistent with other studies that question whether the early response to DNA damage is essential for $\mathrm{p} 53$ to function as a tumour suppressor, and further support the key function of the $\mathrm{p} 19^{\mathrm{ARF}}$ pathway in suppressing tumour development.

Nicola McCarthy

ORIGINAL RESEARCH PAPERS Christophorou M. A., Ringhausen, I., Finch, A. J., Brown-Swigart, L. \& Evan, G.I. The pathological response to DNA damage does not contribute to $\mathrm{p} 53$-mediated tumour suppression. Nature 443, 214-217 (2006) | Efeyan A. et al. Policing of oncogene activity by p53. Nature 443, 159 (2006)

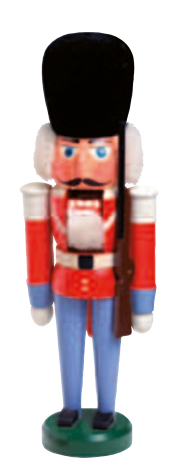

